\title{
Evaluación del Desempeño Docente: Representaciones Sociales elaboradas por educadoras
}

\author{
Teacher Performance Evaluation: Social Representations elaborated by \\ early childhood teachers
}

Mtra. Leticia Reyes Hernández*

Dra. María Isabel Arbesú García**

\section{RESUMEN}

Este artículo se deriva de una investigación doctoral cuyo propósito es identificar las Representaciones Sociales construidas por maestras de educación preescolar acerca de la Evaluación del Desempeño Docente implementada en la Reforma Educativa de 2013. Para lograr este objetivo se diseñó un estudio cualitativo, basado en el enfoque procesual de la Teoría de las Representaciones Sociales que implicó reconocer los significados construidos por las docentes, así como las condiciones culturales, sociales e históricas que influyeron en dicha construcción. Se seleccionó una zona escolar del estado de Veracruz que está integrada por 50 educadoras. A través de diferentes métodos como la entrevista en profundidad, el cuestionario de preguntas abiertas, la técnica de asociación de palabras y el grupo de discusión se construyeron los datos, que fueron abordados mediante el análisis tipológico. Los resultados muestran que las profesoras han construido una representación social sobre la evaluación docente alrededor de dos significados aparentemente opuestos. Por una parte, consideran que la evaluación docente es una herramienta que permitirá mejorar su práctica, sin embargo, también piensan que esta tiene como finalidad perjudicar sus condiciones laborales. Existe una actitud de desconfianza y temor hacia la evaluación docente porque las educadoras suponen que el proceso no será transparente, que habrá corrupción, como en otros modelos de evaluación previos. En conclusión, reconocer el significado que la evaluación tiene para las profesoras permite identificar qué aspectos de este proceso pudieran mejorarse para que logre coadyuvar a la mejora de la calidad educativa.

Palabras clave: evaluación docente, representación social, educación preescolar.

\section{ABSTRACT}

This paper is derived from a doctoral research whose purpose is to identify the Social Representations built by teachers of early childhood education about the Teaching Performance Evaluation implemented in the Educational Reform of 2013. To achieve this objective a qualitative study was designed, based on the processual approach of the Theory of Social Representations, which implied recognizing the meanings constructed by the teachers, as well as the cultural, social and historical conditions that influenced such a construction. A school zone in the state of Veracruz was selected, which is comprised of 50 educators. Through different methods such as in-depth interview, open-ended questionnaire, word association technique and discussion group were constructed the data, which were addressed through typological analysis. The results show that teachers have built a social representation on teacher evaluation around two apparently opposing meanings. On the one hand, they consider that teacher evaluation is a tool that will improve their practice, however, they also think that it is intended to undermine their working conditions. There is an attitude of mistrust and fear of teacher evaluation as educators assume that the process will not be transparent, that there will be corruption, as in other previous evaluation models. In conclusion, recognizing the meaning that the evaluation has for teachers allows identifying which aspects of this process could get better so that it contributes to the improvement of educational quality.

Keywords: teacher evaluation, social representations, early childhood education.

*Benemérita Escuela Normal Veracruzana "Enrique C. Rébsamen" Retorno Díaz Mirón 20

Coatepec, Ver.

CP. 91500

Tel. 2281136287

letyreyes23@gmail.com

**Dra. María Isabel Arbesú García**

UAM-Xochimilco

Fuentes Brotantes 90-2

Colonia Santa Ursula Xitla

Tlalpan CP 14420

Ciudad de México

Tel. 5519521008

Isabel.arbesu@gmail.com 
Perspectivas Docentes 63

Evaluación del Desempeño Docente: Representaciones Sociales elaboradas por educadoras

Teacher Performance Evaluation: Social Representations elaborated by early childhood teachers

Mtra. Leticia Reyes Hernández ${ }^{*}$ / Dra. Maria Isabel Arbesú García**

\section{INTRODUCCIÓN}

En México, ante los resultados nacionales e internacionales poco alentadores de las evaluaciones de logro educativo de los estudiantes, se han diseñado políticas educativas tendientes a evaluar el desempeño de los docentes, ya que se les considera una variable determinante en la promoción de aprendizajes. En ese sentido, una de las primeras acciones realizadas por la administración del presidente Enrique Peña Nieto fue impulsar una Reforma Educativa ${ }^{1}$ centrada, entre otros aspectos, en la creación de un proceso obligatorio de Evaluación del Desempeño Docente, cuya intención consiste en mejorar la calidad del servicio educativo a través de la regulación del ingreso, la promoción, el reconocimiento y la permanencia de los profesores de educación básica y media superior.

Si bien algunos sectores de la sociedad recibieron con agrado la propuesta, el gremio magisterial mostró un rechazo ante la reforma, específicamente en torno a las disposiciones que impactan los derechos laborales. Uno de los aspectos más controversiales es que, si los docentes no aprueban la evaluación del desempeño se podría dar por terminada la relación laboral, sin ninguna responsabilidad para la autoridad. No obstante que los docentes en México están familiarizados con la evaluación, el anuncio de la implementación del Servicio Profesional Docente ${ }^{2}$ y la Evaluación del Desempeño Docente ${ }^{3}$ generó reacciones negativas acerca de la evaluación y las regulaciones laborales que esta reforma pretendía.

Considerando que la RE, busca mejorar la calidad de la educación en México, a través de la evaluación y profesionalización de los docentes, sería deseable que sus opiniones fueran consideradas, de tal forma que existiera un mayor compromiso y disposición para transformar la práctica. Sin embargo, pareciera que la reforma ha sido impuesta a un magisterio que se resiste a los planteamientos de la autoridad, ¿cómo se puede explicar esta reacción?, ¿qué significado atribuyen los docentes a la Evaluación del Desempeño Docente propuesta en la Reforma Educativa?

La postura del magisterio ante la EDD no puede ser juzgada sin tomar en cuenta las experiencias y la subjetividad de los profesores, es necesario comprender qué significados le atribuyen a este proceso. Para lograr esto, se llevó a cabo

\footnotetext{
1 RE a partir de ahora.

$2 \quad$ SPD a partir de ahora.

3 EDD a partir de ahora.
}

una investigación la cual pretende responder a la siguiente pregunta: ¿qué Representaciones Sociales ${ }^{4}$ han construido las educadoras de una zona escolar acerca de la Evaluación del Desempeño Docente?

\section{LA EVALUACIÓN DOCENTE EN MÉXICO}

Al hacer un análisis de cómo la evaluación educativa se ha implementado y ha evolucionando en México, es posible identificar que las primeras actividades de evaluación se centraron en medir los aprendizajes de los alumnos, así como en el diseño de instrumentos que facilitaran la selección/ exclusión a niveles educativos superiores. Es a partir de finales del siglo XX cuando se observa la implementación de procesos de evaluación docente, sobre todo con la finalidad de asignar incentivos económicos y organizar las promociones laborales.

Previo a la implementación de la RE de 2013, en la que la evaluación docente adquiere una relevancia significativa, se establecieron dos acuerdos entre las autoridades educativas y sindicales: el Acuerdo para la Modernización de la Educación Básica y la Alianza por la Calidad de la Educación. Ambos documentos incluyeron mecanismos de evaluación docente que pretendían mejorar la calidad del servicio educativo a través de diversos procesos.

\section{CARRERA MAGISTERIAL}

El programa Carrera Magisterial surgió en el año 1992, como parte del Acuerdo Nacional para la Modernización de la Educación Básica (ANMEB) firmado por la Secretaría de Educación Pública (SEP) y el Sindicato Nacional de Trabajadores de la Educación (SNTE). La Carrera Magisterial funcionó como un sistema de incentivos económicos el cual consistía en promociones de tipo vertical organizadas en cinco niveles. Los factores que se valoraban eran: antigüedad, grado académico, preparación profesional, cursos de actualización y superación profesional, desempeño profesional y aprovechamiento escolar. Si bien la participación en el programa era voluntaria, un gran número de docentes optaron por inscribirse porque los incrementos salariales eran considerables, por ejemplo, quienes lograran alcanzar el nivel E recibían 197\% más ingresos que el personal con salario base (Ortiz, 2003).

$4 \quad$ RS a partir de ahora 
Perspectivas Docentes 63

Evaluación del Desempeño Docente: Representaciones Sociales elaboradas por educadoras

Teacher Performance Evaluation: Social Representations elaborated by early childhood teachers

Mtra. Leticia Reyes Hernández* / Dra. María Isabel Arbesú Garcia**

A pesar de ser una opción para mejorar las condiciones salariales, el programa de Carrera Magisterial recibió diversas críticas, entre ellas, el hecho de no tener un impacto directo en la calidad de la educación (Santibañez, Martínez, Datar, McEwan, Mesan-Setodji y Basurto-Dávila, 2006), así como estar asociado a la corrupción y prácticas poco éticas. Además, generó frustración entre los profesores, quienes llamaban al programa Barrera Profesional pues consideraban que la evaluación era demasiado confusa y la intención era impedir el ingreso a los niveles superiores.

\section{EVALUACIÓN UNIVERSAL}

En el año 2011, la SEP y el SNTE firmaron el Acuerdo para la Evaluación Universal de Docentes y Directivos en Servicio de Educación Básica, mismo que se derivó de la Alianza por la Calidad de la Educación. Este acuerdo surge de la necesidad de contar con una evaluación integral de las competencias y el desempeño de los docentes de educación básica que permitiera articular opciones de formación a partir de las necesidades identificadas, es decir, la evaluación tenía una función formativa, dirigida al diseño de estrategias de profesionalización (SEP-SNTE, 2011).

La Evaluación Universal tenía el carácter de obligatoria y periódica, cada tres años se debía realizar. En el acuerdo se estipuló que en el año 2012, la educación primaria debía evaluarse; en 2013, secundaria; en 2014, la educación preescolar, inicial y especial. Sin embargo, esta calendarización no se implementó debido a la entrada en vigor del SPD. Los aspectos evaluados eran: aprovechamiento escolar, preparación profesional, desempeño profesional y formación continua. En el mismo acuerdo se dejaba en claro que, a partir de los resultados de la Evaluación Universal, se diseñarían programas de formación semipresenciales, presenciales, así como asesorías en línea, abiertos y a distancia.

\section{PROGRAMA DE ESTÍMULOS A LA CALIDAD DOCENTE}

Aunado a la Evaluación Universal, el programa de Estímulos a la Calidad Docente se derivó de la Alianza por la Calidad de la Educación. Éste tenía la finalidad de incentivar a los profesores cuyos alumnos obtuvieran los mejores resultados en la Evaluación Nacional del Logro Académico en Centros Escolares (ENLACE) $)^{5}$, así como a quienes alcanzaran los

5 ENLACE es una prueba de tipo censal que se aplicó, desde puntajes más altos en el factor Preparación Profesional de Carrera Magisterial.

La participación podía ser de manera individual o colectiva porque los estímulos se otorgaban a aquellas instituciones que, de manera general, obtuvieran buenos resultados o bien mejoraran significativamente los puntajes de años anteriores. Por otra parte, el programa hacía una distinción entre las localidades y el grado de marginalidad; esto impactaba en la fórmula que se utilizaba para asignar los estímulos.

\section{LA EVALUACIÓN DEL DESEMPEÑO DOCENTE PLANTEADA EN LA REFORMA EDUCATIVA}

La propuesta de Reforma Educativa fue una de las primeras acciones realizadas por el presidente Enrique Peña Nieto al asumir la presidencia, en diciembre de 2012. Esta contemplaba, entre otras cosas, el otorgamiento de autonomía al Instituto Nacional para la Evaluación de la Educación (INEE) así como la creación del Servicio Profesional Docente, y que tuviera como eje: centrar la evaluación docente como un mecanismo que regulara el ingreso, la promoción y la permanencia en el servicio de los profesores de educación básica y media superior.

En febrero de 2013 se aprobó -en lo general- la RE; posteriormente en el mes de septiembre se aprobaron las leyes secundarias, incluída la Ley General del Servicio Profesional Docente ${ }^{6}$, de la que se derivan los lineamientos que rigen el SPD, así como los criterios, términos y las condiciones para ingresar, permanecer y promover en el servicio (DOF, 2013).

\section{Se denomina Servicio Profesional Docente:}

Al conjunto de actividades y mecanismos para el Ingreso, la Promoción, el Reconocimiento y la Permanencia en el servicio público educativo y el impulso a la formación continua, con la finalidad de garantizar la idoneidad de los conocimientos y capacidades del Personal Docente y del Personal con Funciones de Dirección y de Supervisión en la Educación Básica y Media Superior que imparta el Estado y sus Organismos Descentralizados. (DOF, 2013, $s / p)$

el año 2006, a planteles tanto públicos como privados de los niveles de educación básica y media superior, con la intención de obtener información comparable sobre los conocimientos y habilidades de los estudiantes acerca de los temas evaluados.

$6 \quad$ LGSPD a partir de ahora. 
Perspectivas Docentes 63

Evaluación del Desempeño Docente: Representaciones Sociales elaboradas por educadoras

Teacher Performance Evaluation: Social Representations elaborated by early childhood teachers

Mtra. Leticia Reyes Hernández ${ }^{*}$ / Dra. María Isabel Arbesú García**

Los propósitos del SPD son recurrir a la evaluación como una vía para mejorar la práctica profesional, pues se espera que esta permita reconocer la idoneidad de los conocimientos y capacidades tanto de docentes como del personal directivo y de supervisión. Asimismo, ésta incluye diseñar estrategias que garanticen la formación, la capacitación y la actualización, además de la creación de un programa de estímulos e incentivos que promuevan el desempeño eficiente.

La elaboración de los perfiles, parámetros e indicadores que definen la idoneidad de los docentes, directivos y personal de supervisión, quedó a cargo de la autoridad educativa y del INEE, quienes organizaron en cinco dimensiones lo que debe hacer y saber un profesor. Por otra parte, durante el primer ciclo de implementación de la EDD, se dio a conocer que ésta se realizaría a través de cinco etapas: a) la elaboración de un informe de cumplimiento de responsabilidades profesionales; b) la realización de un expediente de evidencias de enseñanza; c) la presentación de examen de conocimientos y competencias didácticas, d) planeación didáctica argumentada; y e) un examen complementario para quienes requieran acreditar el dominio de una segunda lengua.

Si en la LGSPD se habla de una evaluación interna que será realizada en conjunto con los directivos de las escuelas, el peso mayor se atribuye al proceso externo que se efectuará a través del INEE en coordinación con las autoridades educativas estatales. La EDD es obligatoria y permanente, es necesario destacar que quienes no demuestren un nivel de desempeño docente idóneo o suficiente en las evaluaciones correspondientes, serán removidos de su función, sin responsabilidad para la autoridad; condición que se incluye por primera vez en un programa de evaluación docente.

No obstante que el propósito central del SPD es mejorar la práctica de los profesores, es innegable que las implicaciones de los mecanismos de evaluación propuestos son de tipo laboral ya que ninguna otra propuesta anterior sugería el despido de aquellos maestros que no cumplieran con los perfiles definidos por la autoridad. Por otra parte, el carácter constitucional que se otorgó a esta reforma, así como la poca participación del sindicato, fueron aspectos que diferencian a este modelo evaluativo de los precedentes.

\section{PROPUESTA TEÓRICO-METODOLÓGICA DE LAS REPRESENTACIONES SOCIALES}

Como se ha mencionado antes, lo que nos interesa en este trabajo es identificar el punto de vista de las educadoras acerca de la evaluación de la docencia, por tal motivo se decidió adoptar la propuesta teórico-metodológica de las Representaciones Sociales, pues ésta nos permitirá comprender los significados y actitudes que asumen las profesoras acerca de la temática. Las RS detectan esquemas subjetivos de percepción, de valoración y acción, es decir, el centro de interés lo constituyen las percepciones del sujeto, sus vivencias sobre la evaluación docente, por tanto, se privilegia al actor y a su subjetividad.

Serge Moscovici (1979), acuñó el concepto de Representaciones Sociales en su obra el Psicoanálisis su imagen y su público. Para el autor, la RS no es el sentido común, sólo es una forma en la que este se manifiesta; éstas aparecen con el intercambio de ideas, de opiniones que un sujeto hace con otros sujetos, por lo que tienen que ver con los comportamientos de las personas, lo que da pie para decir que las RS no son pensamientos individuales.

Otro punto importante es que las RS son creaciones que no se expresan de una forma mecánica la información circundante. Aclaremos todo ello a partir de dos citas que tomamos del autor.

(...) es una modalidad particular del conocimiento, cuya función es la elaboración de los comportamientos y la comunicación entre los individuos (Moscovici, 1979, p. 17)

(...) es un corpus organizado de conocimientos y una de las actividades psíquicas gracias a las cuales los hombres hacen inteligible la realidad física y social, se integran en un grupo 0 en una relación cotidiana de intercambios, liberan los poderes de su imaginación (Moscovici, 1979, p.18).

Según Jodelet (2008), el carácter innovador de las RS está en: a) su foco en el pensamiento del sentido común; b) su papel en la constitución de la realidad; y c) su complejidad. Las RS se traducen en complejas construcciones sociales que se integran a través de imágenes y de anhelos que tienen las personas de un grupo, comunidad o sociedad (Jodelet, 1986; Palmonari y Doise, 1986; Rouquette, 2000). Éstas representan un cuerpo de conocimientos que permiten hilvanar ideas, clasificar el mundo social y a sus actores, organizar y actuar en el mundo de la vida cotidiana. Es importante mencionar que es en los pequeños espacios de interacción donde se elaboran las RS a través de la comunicación entablada con los amigos, familiares y la difusión de imágenes e ideas transmitidas en los medios de comunicación masiva las convierte en sociales (Carugati y 
Perspectivas Docentes 63

Evaluación del Desempeño Docente: Representaciones Sociales elaboradas por educadoras

Teacher Performance Evaluation: Social Representations elaborated by early childhood teachers

Mtra. Leticia Reyes Hernández ${ }^{*}$ / Dra. María Isabel Arbesú García**

Selleri, 2000). No son una clasificación fría y objetiva emprendida por quienes observan 0 analizan algo 0 a alguien, sino una sustitución en el pensamiento de aquello que se observa o analiza. Las RS no son ajenas a la particularidad social del actor, específicamente, de sus condiciones socioeconómicas y códigos culturales, tales como edad, actividad realizada, información acerca del objeto de representación, entre otras.

De acuerdo con Moscovici (1979), las RS están organizadas por tres dimensiones: 1) la de la información, 2) la de la actitud y, 3) el campo de representación. La primera está relacionada con el nivel de conocimiento sobre el objeto de la representación. La segunda, se refiere a la valoración global (positiva o negativa) hacia el objeto de representación. La tercera, se vincula con la imagen o modelo social del objeto de representación. Por medio del estudio de estas tres dimensiones es que se puede conocer el "corazón colectivo" que se encuentra presente en las opiniones, evaluaciones, proposiciones y "juicios" individuales (Moscovici, 1979, p. 45).

Es importante mencionar que para abordar el estudio de las RS existen dos grandes enfoques: 1) el procesual y 2) el estructural. Banchs (2000) señala que en el primero se parte de una postura cualitativa, como es el caso de este trabajo, en donde lo que interesa conocer es el proceso en que se construyen las RS. Por eso este modo de aproximación pone el énfasis en el proceso social y no sobre los procesos cognitivos. Lo social pone el acento en tres sentidos: a) las condiciones de producción de las representaciones; b) a las condiciones de circulación de éstas, tomando siempre en cuenta el aspecto histórico y social; c) la búsqueda de sentidos o construcción del conocimiento del sentido común. En cuanto al enfoque estructural, lo importante es identificar la organización, así como la estructura de las representaciones. Esto conlleva un doble abordaje: el de su contenido y el de su estructura. De acuerdo con la naturaleza del objeto de estudio, este enfoque busca aprender los mecanismos cognitivos de construcción, así como las funciones, dimensiones y elementos de una estructura cognitiva (Gutiérrez y Piña, 2008).

Optar por el enfoque procesual en la presente investigación nos llevó a puntualizar en la compresión de cómo está constituida las RS acerca de la evaluación docente, sino también cuál es el sentido que tiene para las educadoras este tipo de evaluación, es decir si la viven o no de la misma manera las protagonistas de este trabajo. Asimismo, llevar a cabo un estudio procesual implica identificar las condiciones del contexto histórico, social, cultural y económico en el cual emergen las RS sobre un determinado objeto de representación, puesto que éstas influyen en la construcción que realizan las personas.

En las últimas décadas los investigadores han mostrado interés por realizar estudios orientados por la Teoría de las Representaciones Sociales, específicamente en la investigación educativa, este enfoque ha permitido el acercamiento al conocimiento del sentido común relacionado con diferentes temáticas, entre éstas, la evaluación docente. Hernández (2010), por ejemplo, realizó un estudio de tipo procesual para identificar las RS construidas acerca del programa Carrera Magisterial en profesores de educación secundaria. Por otra parte, Cuevas (2015) y Díaz (2016) se interesaron en abordar las RS que docentes de educación secundaria han elaborado sobre la Reforma Educativa, específicamente sobre la evaluación docente incluida en ésta.

De igual forma, Pérez (2015) indagó las RS de profesores de educación primaria de Chiapas sobre la misma reforma. Es importante destacar que no se encontraron antecedentes de investigaciones sobre el tema que consideraran a los docentes de educación preescolar, por lo que el estudio que se describe en el presente artículo pretende brindar ser un acercamiento a este nivel educativo.

Como se dijo antes, en la Teoría de las Representaciones Sociales, el centro de interés se integra por las experiencias, vivencias y opiniones que tienen los sujetos respecto a algo o a alguien. En el caso que nos ocupa, como también se ha mencionado, lo que nos interesa es conocer y comprender cómo concibe un grupo de educadoras la evaluación del desempeño docente, planteado en la RE.

\section{PROCEDIMIENTO METODOLÓGICO}

Para investigar las RS que las docentes de educación preescolar han elaborado en torno a la EDD se diseñó un estudio cualitativo de alcance interpretativo, ya que este acercamiento permitirá comprender, desde la subjetividad de los actores, las experiencias, posturas y comportamientos de los mismos. Además de tener la intención de recuperar el conocimiento del sentido común que ha sido construido acerca del objeto de representación, nos interesa reconocer las condiciones que han dado origen a éste, es por ello que el estudio se orienta bajo el enfoque procesual. 
Perspectivas Docentes 63

Evaluación del Desempeño Docente: Representaciones Sociales elaboradas por educadoras

Teacher Performance Evaluation: Social Representations elaborated by early childhood teachers

Mtra. Leticia Reyes Hernández* / Dra. María Isabel Arbesú Garcia**

El trabajo de campo se realizó en una zona escolar de la región centro del estado de Veracruz, México, integrada por 44 docentes frente a grupo y 3 directivos $^{7}$, distribuidos en 22 jardines de niños ${ }^{8}$. Las instituciones se distribuyen en cuatro municipios, principalmente se ubican en localidades rurales 0 en zonas urbano marginadas. La plantilla docente es diversa en cuanto a los años de antigüedad en el servicio, la mayoría de las docentes oscila entre el año y los diez años. Por otra parte, todo el personal ha sido formado para la docencia, ya sea en escuelas normales o en universidades pedagógicas; además, algunas cursaron, como primera carrera, una licenciatura en psicología o pedagogía.

Para poder construir los datos se implementó un procedimiento plurimetodológico que consistió en la realización de entrevistas a profundidad, grupos de discusión, asimismo en la aplicación de la técnica de asociación de palabras y de cuestionarios de preguntas abiertas. Los instrumentos se construyeron con el propósito de recuperar las dimensiones de las representaciones sociales, también, se incluyeron elementos que permitieran conocer a las docentes, así como el contexto en el que se encontraban inmersas.

El trabajo de campo se llevó a cabo desde enero de 2015 hasta septiembre de 2016, durante las sesiones de Consejo Técnico, mismas que se realizan cada último viernes del mes. En un primer momento se solicitó a todo el colectivo que respondieran a un cuestionario de preguntas abiertas, asimismo se aplicó la técnica de asociación de palabras. Posteriormente se seleccionó a diez docentes, considerando criterios como la antigüedad en el servicio, la participación en programas de evaluación docente como Carrera Magisterial y en el SPD. Por último, se hizo un grupo de discusión en donde se seleccionó a un grupo preexistente, integrado por seis educadoras que laboraban en tres jardines de niños bidocentes ${ }^{9}$, quienes integraban un colectivo al interior del Consejo Técnico.

El abordaje de los datos se realizó mediante el análisis tipológico, que de acuerdo con Goetz y LeCompte (1988) consiste en la organización de los datos en grupos o categorías

7 En la zona escolar laboran dos educadores, sin embargo, utilizamos el término educadoras para expresarnos porque en su mayoría la zona está integrada por mujeres.

8 Los jardines de niños considerados en este estudio son de sostenimiento público.

9 Los jardines de niños de organización bidocente son aquellos que funcionan a cargo de dos profesores, quienes realizan, además de la función de enseñanza, las tareas relacionadas con la función directiva y de intendencia. las cuales pueden ser diseñadas a partir de marcos teóricos. En este caso, la Teoría de las Representaciones Sociales fue el referente para determinar los ejes de análisis, por lo que se consideraron las dimensiones de información, actitudes, campo de representación, y las prácticas sociales de comunicación y el sistema de creencias y valores (Ibañez, 1994).

\section{CONDICIONES SOCIALES, HISTÓRICAS Y CULTURALES EN LAS QUE EMERGEN LAS RS SOBRE LA EVALUACIÓN DEL DESEMPEÑO DOCENTE.}

La evaluación, como objeto de representación, está presente en la cotidianeidad de las docentes y alumnos porque constantemente se efectúan actividades que tienen como propósito reconocer los aprendizajes, valorar las estrategias de enseñanza, identificar aspectos del desempeño que pueden mejorarse, entre otras cuestiones. En el caso específico de la evaluación docente, como se ha mencionado, el magisterio mexicano ha participado en programas con este fin desde hace varias décadas; sin embargo, al darse a conocer la RE de 2013 y el nuevo proceso de EDD, la evaluación se convirtió en un objeto de representación novedoso, pues el planteamiento de esta nueva ley difería de los programas previos.

Para poder comprender los significados que se construyeron alrededor de la EDD, en forma de RS, es necesario adentrarse en el contexto en el cual éstas se producen, es decir, cuáles fueron las condiciones que intervinieron en su origen. En México, la figura de los profesores de educación básica estaba devaluada, debido a que se les atribuía el bajo rendimiento obtenido por los alumnos en evaluaciones del aprendizaje internacionales, como PISA. Aunado a esto, en octubre de 2012 se difundió la noticia de que los resultados de la primera Evaluación Universal realizada a los docentes y directivos de educación primaria eran reprobatorios, ya que el promedio nacional era de 5.8 (Animal Político, 26-10-2012). En diversos medios de comunicación se resaltaba la deficiencia de preparación de los docentes, que generó múltiples críticas hacia el gremio magisterial.

En este clima se aprobó la RE, una ley polémica debido a que establecía a la evaluación como un mecanismo obligatorio que regularía el ingreso, la promoción y la permanencia de los profesores. En diferentes medios de comunicación se expresaron opiniones al respecto de esta reforma, entre los cuales se destacaba la afirmación de que la reforma era de tipo laboral, más que educativa. 
Perspectivas Docentes 63

Evaluación del Desempeño Docente: Representaciones Sociales elaboradas por educadoras

Teacher Performance Evaluation: Social Representations elaborated by early childhood teachers

Mtra. Leticia Reyes Hernández* / Dra. María Isabel Arbesú Garcia**

Por otra parte, la participación del sindicato (SNTE) no fue la misma que en el establecimiento de acuerdos o alianzas anteriores, de hecho, la líder entonces sindical Elba Esther Gordillo se pronunció en contra de esta reforma; sin embargo, su papel fue limitado porque a finales del mes de febrero de 2013 fue acusada de desvío de recursos y aprehendida. Aunado a este rechazo por parte del SNTE, la Coordinadora Nacional de Trabajadores de la Educación (CNTE) también expresó su oposición a lo que ellos consideraron una reforma laboral, más que una verdadera reforma de planes y programas educativos.

Durante los meses previos al decreto de las leyes secundarias de la RE, la CNTE encabezó protestas, asimismo, una vez que se aprobaron dichas leyes, en diferentes estados de la República se realizaron paros laborales, toma de escuelas, bloqueos a vialidades, entre otras actividades que pretendían demostrar la resistencia del magisterio ante esta reforma. En el estado de Veracruz, específicamente en la zona central -en la que se realizó esta investigación- los profesores tuvieron una participación activa en el movimiento de resistencia, incluso llegaron a presentarse enfrentamientos con las autoridades. El 14 de septiembre por la noche de aquel año, un grupo de maestros fue desalojado de Plaza Lerdo, frente a palacio de Gobierno, por la policía quien utilizó la fuerza; incluso llegó a señalarse que había profesores desaparecidos (Cruz, 2013).

Al finalizar el año 2013 el movimiento de resistencia fue debilitándose, los docentes regresaron a las aulas, sin embargo, el rechazo hacia la EDD, como un mecanismo que pretendía transformar las condiciones de trabajo de los docentes, seguía siendo latente. Es necesario destacar que los procesos de evaluación no se implementaron de manera inmediata, porque solo quienes pretendían ingresar o promoverse fueron evaluados durante el ciclo 2014-2015. Para el ciclo escolar 2015-2016 fue seleccionada una muestra de la población que debía ser evaluada por primera vez, es decir, que hasta esta fecha no todos los docentes han sido evaluados, sin embargo, existe ya un cúmulo de información que circula en torno a este proceso, lo cual dio pie a RE.

Es necesario destacar que, históricamente, quienes laboran como docentes en instituciones oficiales sabían que el empleo estaba asegurado puesto que la plaza se traducía en un nombramiento de planta; garantizaban así que no serían despedidos. Sin embargo, en la LGSPD se menciona que quienes no logren los resultados esperados, después de dos periodos de evaluación, serán removidos de su función, sin responsabilidad para las autoridades. Sin duda, esta nueva condición implica que los profesores ahora podrían perder sus empleos, es decir, que la situación laboral del magisterio ha cambiado.

\section{LA REPRESENTACIÓN SOCIAL SOBRE LA EVALUACIÓN DEL DESEMPEÑO DOCENTE}

La Representación Social que las educadoras de la zona escolar han construido sobre la Evaluación del Desempeño Docente, en primer lugar, se refiere a la finalidad que esta tiene: mejorar la práctica educativa y apoyar la profesionalización de la docencia. En contraparte, también fue posible identificar que existe una imagen de la evaluación como un mecanismo cuya finalidad es sancionar laboralmente a las profesoras, además, representa un proceso que no refleja el desempeño real, que no considera las condiciones y características de las comunidades educativas.

Por otra parte, debido a la corrupción que impera en el país y a las experiencias que las educadoras han tenido en años anteriores con modelos similares, se ha conformado una actitud de desconfianza ante el proceso de evaluación. Dado el carácter obligatorio de la EDD y la condición de la aprobación de la misma para poder conservar el empleo, las educadoras expresan temor porque, ante la imagen de esa evaluación poco fiable y la posibilidad de que exista corrupción, experimentan miedo y estrés por la idea de perder su trabajo. Este miedo se genera de la información que tienen acerca de que la RE y la EDD tiene un carácter laboral, y pretende dejar sin empleo a miles de maestros, de tal forma que el gobierno pueda contratar a nuevos empleados, quienes no tendrán las mismas prestaciones que se tenía anteriormente.

Si bien hay una representación negativa de la evaluación docente, las educadoras expresan que están tomando decisiones que las lleven a cumplir con los requisitos de la EDD, se están preparando para tener los elementos necesarios para lograr los puntajes requeridos para permanecer en sus fuentes de trabajo. La evaluación es considerada por las educadoras como sinónimo de examen, la mayoría de las profesoras plantean que deben estudiar para aprobar este instrumento y de esta forma, conservar sus empleos.

En los siguientes subapartados se describe, con mayor detalle, cada uno de los significados que integran la RS sobre la Evaluación del Desempeño Docente que ha sido construida por las educadoras de la zona escolar. 
Perspectivas Docentes 63

Evaluación del Desempeño Docente: Representaciones Sociales elaboradas por educadoras

Teacher Performance Evaluation: Social Representations elaborated by early childhood teachers

Mtra. Leticia Reyes Hernández ${ }^{*}$ / Dra. María Isabel Arbesú García**

\section{¡EVALUACIÓN SÍ, PERO NO ASÍ!}

La EDD representa para las educadoras un mecanismo que posibilita la mejora de la práctica educativa, que está estrechamente relacionado con la formación y preparación docente. Sin embargo, la información acerca de prácticas de corrupción efectuadas en la implementación de otros programas de evaluación, así como la noción de que los instrumentos de evaluación están alejados de la práctica real, ha generado una imagen negativa del objeto de representación.

Las RS expresan un sentido lógico desde la perspectiva de quien las construye (Piña, 2004), esto se hace evidente al analizar el contenido del campo de representación ya que, por una parte, la finalidad de la evaluación se asocia a la formación profesional y la mejora de la práctica, lo cual denota una imagen positiva pero por otra parte, se asocia con un proceso de evaluación inadecuado, arbitrario, inconsistente, dejando entrever una postura de rechazo.

El significado que atribuyen a la EDD es que permite mejorar la práctica y la calidad de la educación, esto quizá se derive de la información que proviene de los planes y programas de estudio de educación básica, en los cuales se plantea un enfoque de evaluación formativo (SEP, 2011). Asimismo, en los acuerdos firmados como parte de las políticas educativas de las últimas décadas, también se ha hecho alusión a la mejora de los servicios educativos a través de la evaluación docente.

...yo creo que la finalidad es mejorar, mejorar la docencia, la calidad de la educación y mejorar la calidad de la educación es mejorar también a los docentes y capacitarlos [E1 $]^{10}$

Como contraparte a este significado, fue posible identificar que las educadoras asociaron la EDD con un mecanismo desvirtuado que pretende impactar en las condiciones laborales existentes.

No era miedo a la evaluación, era miedo a perder nuestros derechos, era miedo a que esa evaluación es punitiva y siempre lo hemos dicho, siempre; esa evaluación era punitiva, para quitarnos nuestro trabajo [E10].

10 Los diálogos recuperados de los diversos instrumentos se señalan con cógido: E1. entrevista a educadora 1, GDE1. educadora 1 del grupo de discusión. P1.E1. Pregunta1 del cuestionario.Educadora1
La información acerca de este proceso gira alrededor del carácter obligatorio, así como a la posibilidad de ser separado de la función, en caso de que no se obtenga un puntaje satisfactorio.

...creo que ese es el problema que nos dicen que hay una evaluación para mejorar la educación, pero nosotros sabemos que solo es una evaluación para ver si te puedes quedar con tu trabajo o no; no para mejorar la educación [E3].

Si bien parecieran dos imágenes o significados contrarios, es posible interpretar que, por una parte, existe un reconocimiento de la evaluación como medio para mejorar, pero en el sentido opuesto, se considera que los nuevos procesos de evaluación tienen una intención alejada de la función formativa. El aspecto central del SPD que circuló en diferentes medios de comunicación, en redes sociales, así como en las conversaciones entres los profesores fue que la RE tenía una intención laboral.

\section{¿AHORA TAMBIÉN HABRÁ CORRUPCIÓN?}

Las experiencias negativas con programas de evaluación docente, como Carrera Magisterial, así como la información proveniente acerca de la corrupción que existe actualmente en México, ha generado una actitud de desconfianza en las educadoras. Se desconfía de las autoridades, de los procedimientos e instrumentos de evaluación, de la ética de los propios profesores, y del manejo que se le pueda dar a los resultados obtenidos de la EDD. Considerando que en otros programas de evaluación, y que en distintos ámbitos institucionales existe la corrupción, asumen que esta práctica estará presente en el nuevo modelo de evaluación.

No sólo se desconfía de las autoridades, de igual forma, las docentes relataron experiencias en las que sus compañeros incurrieron en prácticas poco éticas, con la finalidad de cumplir con los requisitos solicitados como parte del proceso de evaluación.

algunas fueron muy honestas en el expediente que enviaron, porque realmente era de sus niños, de lo que hicieron con sus niños, y también sé de maestras que vieron la manera de que todo estuviera precioso pero finalmente ellas no hicieron nada, las ayudaron para que ese expediente cumpliera con lo que estaban pidiendo, pero ella ni siquiera lo hicieron. [E8] 
Perspectivas Docentes 63

Evaluación del Desempeño Docente: Representaciones Sociales elaboradas por educadoras

Teacher Performance Evaluation: Social Representations elaborated by early childhood teachers

Mtra. Leticia Reyes Hernández ${ }^{*}$ / Dra. María Isabel Arbesú García**

La información que tienen las educadoras es que la EDD se realizará a través de medios electrónicos, por ejemplo, el examen de conocimientos se llevará a cabo por computadora, esto genera una desconfianza pues consideran que se podrían generar prácticas poco éticas.

...en las redes sociales pasaron unos videos que estaban pues bien concentrados los maestros y de repente, se caía el sistema y ¿entonces ahí quién te garantiza que lo que tú ya hiciste de verdad corresponda a tu nombre o a otra persona?... [E8]

Sin duda, la información que tienen de prácticas poco éticas de programas de evaluación docente, como Carrera Magisterial, ha propociado que las docentes muestren una actitud de desconfianza en el proceso, así como en las autoridades y en los propios docentes. Consideran que puede no haber transparencia en la EDD, lo que genera temor porque está en juego la permanencia en su trabajo y la fuente de ingresos que les permite ser un sustento económico para su familia.

\section{UNA EVALUACIÓN ALEJADA DE LA REALIDAD EDUCATIVA}

Si no todas las profesoras han sido evaluadas, sí han obtenido información por parte de quienes han presentado la evaluación, así como de comentarios que circulan en redes sociales y medios de comunicación. La información que tienen las docentes acerca de la EDD es que ésta no se relaciona con la realidad educativa, específicamente con aquella que se vive en los jardines de niños rurales, ya que no se consideran las condiciones y los contextos en los que se sitúan.

Opino que la Evaluación del Desempeño Docente propuesta por las autoridades es un mecanismo retirado de la realidad y la cotidianeidad de la vida y procesos que se dan en la escuela, donde realmente se dan las mejoras" [P7_E34].

La imagen que han construido las educadoras acerca de la EDD es que ésta se centra en la práctica educativa en condiciones ideales, ellas en lo particular se sienten fuera de esta realidad idonea ya que en muchos de los contextos en los que laboran predominan las condiciones de pobreza y/o marginalidad.

Entonces siento que esos aspectos ellos no los toman en cuenta, no toman en cuenta que el jardín no tiene recursos, no toman en cuenta la situación de las familias que integran el plantel, o sea ellos están en su realidad de una escuela con cierto protocolo que está completo, una escuela completa que tiene todos los beneficio, tiene todos los recursos entonces siento que esto tampoco lo toman en cuenta. [E1]

Las docentes opinan que existe un desconocimiento de la realidad educativa por parte de quienes elaboran los instrumentos y mecanismos de EDD. En los diálogos de las educadoras se percibe un aprecio por la labor que realizan, reconocen que existen diversos factores que impactan tanto en el aprendizaje de los niños, como en el propio desempeño, aspectos que no son considerados por las autoridades educativas, quienes ante sus ojos son personas que están detrás de un escritorio, en una realidad completamente ajena a la que ellas viven cotidianamente.

detrás de quien hace esas evaluaciones no son quienes están en práctica, son pedagogos que a lo mejor están ahí, están en una realidad, no están en la realidad, no están yendo a la comunidad, no se van caminando dos horas para llegar al jardín, no ven que el niño llega sin desayunar, o sea, no ven nada [E7].

Como se mencionó anteriormente, las educadoras asumen que quienes realizan la EDD no conocen la realidad eduativa, por lo tanto, ellas piensan que los perfiles y parámetros que se han establecido como referente para la evaluación no describen la tarea que un profesor en condiciones adversas realiza. Por otra parte, saben que una evaluación del desempeño implica observar la práctica de un docente en una situación real, es por ello que opinan que la EDD no refleja realmente todos los aspectos de la docencia, solo algunos.

digo es imposible que se pueda hacer una evaluación sobre el desempeño docente real, porque entonces tendrías que tener a una persona viéndote las 24 horas del día. Porque además puede ser que un día de plano te salió todo mal y al otro te salga todo bien, o sea, no, ni siquiera creo que pueda haber un estándar de decir en estas cosas está bien y en estas cosas no. Depende de muchas cosas, entonces y pues es lo que no se toma en cuenta. [E3]

Por otra parte, para los docentes, el hecho de responder satisfactoriamente un examen no es sinónimo de ser un buen profesor, es decir, opinan que los instrumentos planteados en la EDD no son capaces de reflejar las competencias docentes. 
Perspectivas Docentes 63

Evaluación del Desempeño Docente: Representaciones Sociales elaboradas por educadoras

Teacher Performance Evaluation: Social Representations elaborated by early childhood teachers

Mtra. Leticia Reyes Hernández ${ }^{*}$ / Dra. María Isabel Arbesú García**

Se conocen casos de maestros que a nivel numérico pueden ser excelentes, es decir de diez, hablando en términos específicos, pero ya al verlos en el trabajo de campo, la verdad es que dejan mucho que desear porque las conductas son realmente negativas o no son las que se esperan de un docente [E4].

...yo conozco maestras que no saben redactar, pero qué bien dan sus clases, entonces por eso no podemos catalogar a la persona, ahora si ni por lo que escribe, ni por una computadora, sino más bien, por su desempeño real. [E8]

En estos comentarios es posible identificar que las docentes consideran que la evaluación del desempeño implica que alguien observe la práctica en las condiciones reales y, a partir de esta observación, les pueda brindar retroalimentación que parta de las necesidades de cada contexto educativo y de los requerimientos de aprendizaje de los alumnos. La RS que tienen las educadoras sobre la EDD propuesta en la RE es que los mecanismos implementados no ha diseñado un proceso que permita un acercamiento real a la práctica educativa, por lo tanto no se puede conocer lo que en realidad sucede en las aulas.

\section{PREPARARSE PARA APROBAR EL EXAMEN: ASEGURANDO EL EMPLEO}

Las RS orientan los comportamientos de las personas, es decir, que a partir de la información que poseen, toman una postura ante los fenómenos sociales y asimismo, deciden de qué forma actuarán ante estos. Ya que la EDD implementada a partir de la RE 2013 tiene un carácter obligatorio, las educadoras de la zona escolar, considerando la información que obtuvieron, han decidido que deben prepararse para obtener puntajes aprobatorios, lo cual les permitirá permanecer en sus empleos.

Ahora que mi desempeño será evaluado, estoy pensando realizar las siguientes acciones: estoy iniciando un diplomado con el fin de centrarme en lo que supuestamente vendrá en el examen [P10_E31]

Las profesoras tienen información acerca de cursos que se imparten en la región, de manera particular, los cuales ofrecen preparar al magisterio a través de simuladores del examen, así como en aspectos como la planeación argumentada y la elaboración del portafolio de evidencias, instrumentos considerados en el proceso de EDD.
... en el curso que estuve, que fue de septiembre a enero, los sábados, de septiembre del 2015 a enero de este año, abarcamos muchas cosas. No leí todo, la verdad, porque era bastante pero pues algo, lo que pudimos abarcar, pues 10 hicimos y los exámenes que te digo que me pusieron a manera de simulacros, pues también me sirvieron [E8]

Y me inscribí, últimamente en un curso de planeación didáctica argumentada, entonces, son cosas, que digo: eso ya lo hace uno, este, pues si ya lo haces, pero no como lo están pidiendo, con todos los elementos que te están pidiendo ahí, no? Entonces digo, de alguna manera pues me sirve [E9]

Si la intención de las autoridades es mejorar la calidad de la práctica docente y del servicio educativo a través de la reforma implementada, la mayoría de las docentes tiene en mente buscar opciones de formación que les permitan tener los elementos necesarios para aprobar el proceso. Es decir que la intención de las profesoras, más que llevar a cabo acciones para mejorar su desempeño, pretenden optar por cursos y por estrategias que les ayuden a obtener los puntajes necesarios para no perder sus empleos.

\section{CONSIDERACIONES FINALES}

La Evaluación del Desempeño Docente, propuesta como parte de la Reforma Educativa impulsada por la administración del presidente Peña Nieto, ha generado en la sociedad mexicana reacciones diversas y puntos de vista opuestos en torno a su aplicación. El notorio rechazo por parte del gremio magisterial ante esta medida planteada por las autoridades pudiera interpretarse como la resistencia a ser evaluados, a modificar la práctica docente y, por lo tanto, a concretar el propósito de la reforma: mejorar la calidad del servicio educativo. Sin embargo, el sentido de esta investigación ha sido profundizar en las expresiones de rechazo de los profesores para comprender qué significado tiene para ellos esta política educativa.

La investigación realizada nos permitió reconocer que, detrás del aparente rechazo hacia la evaluación docente, por parte del gremio magisterial, existen aspectos relacionados con la desconfianza por parte del sector educativo en los mecanismos implementados anteriormente. En el caso específico de las educadoras participantes en este estudio, se pudo identificar que, si bien están conscientes de que la evaluación de la docencia es una estrategia que va de la mano de la profesionalización, también reconocen que es un proceso que 
Perspectivas Docentes 63

Evaluación del Desempeño Docente: Representaciones Sociales elaboradas por educadoras

Teacher Performance Evaluation: Social Representations elaborated by early childhood teachers

Mtra. Leticia Reyes Hernández* / Dra. María Isabel Arbesú Garcia**

puede conducir a la mejora del servicio, existe una postura de desaprobación.

Estas opiniones son resultado de la desconfianza, de la información de prácticas poco éticas y de corrupción que se asocian a otros programas, así como a la sensación de que los mecanismos propuestos no permitirán captar el desempeño real de los docentes, es decir, se considera que la realidad que se vive en las aulas, no se verá reflejada en los resultados del proceso de EDD planteado en la reforma.

Por lo anterior, prevalece una actitud de temor ante las consecuencias planteadas en la LGSPD ya que en caso de que un docente no obtenga un resultado satisfactorio, puede ser removido de sus funciones, factor que representa una pérdida de la fuente de empleo y, por lo tanto, del ingreso que les permite a los profesores ser el sostén de sus familias.

Si bien los mecanismos de evaluación docente planteados en la $R E$ son recientes, es innegable que la evaluación de la docencia es un objeto de representación que ha estado presente en diversos momentos de la vida profesional del magisterio, es por ello que la información que se ha incorporado a la RS sobre la EDD recupera elementos históricos y experiencias previas de las educadoras, incluso aquellas vividas desde la etapa de escolaridad.

A través de esta investigación también fue posible reconocer que las educadoras tienen una noción de lo que significa desempeñarse como docentes, que implica no solo generar ambientes de aprendizaje, sino también responder a las necesidades de las comunidades en las que laboran. Es decir que las profesoras consideran que ser docente no es solo seguir al pie de la letra un programa de estudio, la tarea es más compleja porque deben adecuar las estrategias didácticas para atender esas necesidades de quienes viven en comunidades con cierto tipo de rezagos. Esta complejidad, desde el punto de vista de las docentes, no puede ser percibida por la serie de técnicas e instrumentos de evaluación propuestas en la EDD, es decir, consideran que el acercamiento para evaluar su desempeño debiera ser diferente, si realmente se espera contar con un diagnóstico y una valoración confiable de las prácticas en condiciones reales.

Desde esta perspectiva, podríamos afirmar que si las políticas públicas propuestas para mejorar la calidad educativa a través de la evaluación y profesionalización de los docentes no comparten esta idea de complejidad de la docencia, probablemente será una visión parcial. Igualmente si partimos del reconocimiento que tiene, para un sistema educativo, el papel del docente en el proceso de aprendizaje de los estudiantes, entonces se tendría que considerar que la participación comprometida y convencida de los educadores en las reformas educativas propuestas será pieza clave en el logro de los propósitos de estas.

Si no se logra involucrar a los docentes, si las estrategias de mejora son impuestas, podría llegar a generarse una participación desde la simulación. Es decir, al ser obligatoria, los profesores participarán en la evaluación de su desempeño, sin embargo, tal como algunas educadoras lo expresaron, se prepararán para aprobar el proceso porque su permanencia en la función depende de ello, pero esto no asegurará una mejora de las prácticas docentes.

Por otra parte, al hacer un análisis del procedimiento metodológico implementado, el cual pretendía identificar el proceso mediante el cual las RS sobre la EDD han sido construidas por las docentes de educación preescolar, podemos concluir que la Teoría de las Representaciones Sociales es un elemento pertinente que facilitó reconocer los significados que tiene la EDD para las profesoras. Sin duda, esta teoría permitió un acercamiento con las construcciones individuales, siendo también el análisis de los aspectos sociales, culturales e históricos un elemento que facilitó la identificación del proceso mediante el cual las docentes se han apropiado de información, y que les ha llevado a tomar determinada postura.

Hasta el momento, son pocos los estudios que se han realizado para indagar las RS construidas sobre la EDD. Existen investigaciones que exploran las opiniones de los docentes evaluados, en relación con el proceso de notificación, la implementación de las etapas y el informe de resultados (INEE, 2016); aspectos que resultan de interés, pero son limitados puesto que no contemplan la postura hacia todo el contenido de la LGSPD ni pretenden comprender el origen de las opiniones.

Es necesario reconocer que el objetivo de esta investigación no es generalizar los resultados, porque las RS que las educadoras participantes de este estudio responden a sus vivencias y experiencias, así como a las circunstancias que les caracterizan. A partir de esta consideración, reconocemos que estudios como el que aquí se presenta podrían ser llevados a cabo en otros niveles y modalidades educativos, con la finalidad de conocer si las RS son compartidas, o bien, no existen 
Perspectivas Docentes 63

Evaluación del Desempeño Docente: Representaciones Sociales elaboradas por educadoras

Teacher Performance Evaluation: Social Representations elaborated by early childhood teachers

Mtra. Leticia Reyes Hernández ${ }^{*}$ / Dra. María Isabel Arbesú García**

similitudes. Asimismo, otra línea de investigación que podría derivarse de este estudio, se relaciona con la comparación de las RS que son construidas acerca de la EDD por parte de los docentes con mayor antigüedad y quienes recién ingresan al servicio, ya que podrían ser diferentes las posturas debido a que las nuevas generaciones no han tenido experiencias con programas de evaluación anteriores.

No obstante que esta investigación pretende tener un alcance interpretativo y brindar elementos para la comprensión, no podemos omitir plantear ciertas recomendaciones que pudieran impactar en las políticas educativas. En primer lugar, como se mencionó anteriormente, si se reconoce que el docente tiene un papel medular en el logro de los aprendizajes de los estudiantes, las autoridades educativas debieran promover la participación activa de este sector, de tal forma que sus propuestas fueran incorporadas a las estrategias de mejora. De esta forma, los profesores serían copartícipes, generando así una implicación más auténtica en el logro de la calidad educativa.

\section{SEMBLANZA DE LOS AUTORES:}

Mtra. Leticia Reyes Hernández

Actualmente labora como docente en la Benemérita Escuela Normal Veracruzana "Enrique C. Rébsamen", en la licenciatura en Educación Preescolar. Estudió la maestría en Educación en el ITESM, así mismo, realizó estudios de doctorado en la Universidad Autónoma de Tlaxcala. Su línea de investigación aborda la Evaluación de la docencia y las Representaciones Sociales de los actores educativos.

\section{Dra. María Isabel Arbesú García}

Profesora e investigadora titular de la Universidad Autónoma Metropolitana, Unidad Xochimilco. Doctora en Educación por la Universidad Autónoma de Morelos, Cuernavaca, México. Su línea de investigación aborda la Evaluación de la docencia en la Educación Superior y las Representaciones Sociales.

\section{REFERENCIAS BIBLIOGRÁFICAS:}

Animal Político (26 de octubre de 2012). Maestros reprueban Evaluación Universal. Animal Político. Recuperado de http:// www.animalpolitico.com/2012/10/maestros-reprueban-laevaluacion-universal/

Banchs, M. A. (2000). Aproximaciones procesuales y estructurales al estudio de las Representaciones Sociales, en Paper on Social Representations, 9, 3-1. - 3-15. Recuperado de http://www.psr.jku.at/PSR2000/9_3Banch.pdf

Carugati, F. y Selleri P. (2000). Pratiques éducatives, socialization et représentations sociales. En C. Garnier y M. L. Rouquette (Eds.). Représentations sociales et éducation, pp. 1-25. Montreal, Canada: Éditions Nouvelles.

Cruz, E. (14 de septiembre de 2013). La policía de Veracruz desaloja plantón de profesores. Expansión. Recuperado de http://expansion.mx/nacional/2013/09/14/la-policia-deveracruz-desaloja-por-la-fuerza-a-profesores-de-la-cnte

Cuevas, Y.M. (2015). La Reforma Educativa 2013: Representaciones Sociales de docentes de secundaria. Ponencia presentada en el XIII Congreso Nacional de Investigación Educativa. COMIE. Chihuahua, México.

Díaz, F. (2016). Las representaciones sociales del profesorado de telesecundarias sobre la evaluación docente en la reforma educativa 2013. Ponencia presentada en el Congreso Internacional de Educación. Debates en Evaluación y Currículum. Tlaxcala, México. Recuperado de http:/l posgradoeducacionuatx.org/pdf2016/C030.pdf

DOF (2013, 11 de septiembre). Decreto por el que se expide la Ley General del Servicio Profesional Docente [en línea]. Recuperado de http://www.dof.gob.mx/nota_detalle. php?codigo $=5313843 \&$ fecha $=11 / 09 / 2013$

Goetz, Judith y LeCompte, Margaret. (1988). Etnografía y diseño cualitativo en investigación cualitativa. España, Madrid: Morata.

Gutiérrez, S. y Piña, J.M. (2008). Representaciones sociales: teoría y métodos. En M.I. Arbesú, S. Gutiérrez y J.M. Piña 
Perspectivas Docentes 63

Evaluación del Desempeño Docente: Representaciones Sociales elaboradas por educadoras

Teacher Performance Evaluation: Social Representations elaborated by early childhood teachers

Mtra. Leticia Reyes Hernández ${ }^{*}$ / Dra. María Isabel Arbesú García**

(Coords.), Educación Superior. Representaciones sociales (pp.13-48). México: Gernika.

Hernández, S. (2010). Evaluación de la educación. Representaciones sociales sobre el programa de carrera magisterial. Ponencia presentada en el Congreso Iberoamericano de Educación. Metas 2021. Argentina. Recuperado de http://www.adeepra.org.ar/congresos/ Congreso\%20IBEROAMERICANO/EVALUACION/R1742b_ Hernandez.pdf

Ibañez, T. (1994). Psicología social construccionista. México: Universidad de Guadalajara.

Jodelet, D. (1986). Las representaciones sociales: fenómenos, conceptos y teoría (Trad. D. Rosenbaum). en Serge Moscovici (Coord.), Psicología Social II, pp. 469-494. Barcelona, España: Paidós.

(2008). El movimiento de retorno al sujeto y el enfoque de las representaciones sociales. Cultura y representaciones sociales, 3 (5), 32-63. Recuperado de http://www.culturayrs. org.mx/revista/num5/Jodelet.html

INEE (2016). Evaluación del desempeño desde la experiencia de los docentes. Consulta con docentes que participaron en la primera Evaluación del desempeño 2015. México: autor. Recuperado de http://publicaciones.inee.edu.mx/buscadorPub/ P1/F/207/P1F207.pdf

Moscovici, S. (1979). El psicoanálisis, su imagen y su público. (Trad. N.M. Finetti). Buenos Aires, Argentina: Huemul.

Ortiz, Maximino. (2003). Carrera Magisterial. Un proyecto de desarrollo profesional. Cuadernos de discusión 12. México: SEP.

Palmonari, A. y Doise, W. (1986), Caractéristiques des représentations sociales en W. Doise y A. Palmonari (Coords.), L'étude des représentations sociales, pp. 12-33. Paris, Francia : Delachaux \& Niestlé.

Pérez, G.M. (2015). Reforma Educativa Mexicana de 2013: Representaciones Sociales de los docentes de educación primaria en Chiapas. Ponencia presentada en el Congreso
Internacional de Investigación en Derecho Educativo. Chiapas, México. Recuperado de http://www.congresoderechoeducativo. unach.mx/memorias/ciide2015/MEMORIA CIIDE 2015.pdf

Piña, J.M.. (2004). La teoría de las representaciones sociales. Nociones y linderos. En J.M. Piña (Coord), La subjetividad de los actores de la educación. Pp. 15-54. México: UNAM-CESU.

Rouquette, M.L. (2000). Représentations et practiques sociales : une analyse théorique. En C. Garnier y M.L. Rouquette (Eds.). Représentations sociales et éducation, pp. 133-141. Montreal, Canada: Éditions Nouvelles.

Santibañez, L., Martínez, J.F., Datar, A., McEwan, P. J., MesanSetodji, C., Basurto-Dávila, R.. (2006). Haciendo camino. Análisis del sistema de evaluación y del impacto del programa de estímulos docentes Carrera Magisterial en México. USA: RAND Corporation.

SEP (2010). Antecedentes de otros sistemas de estímulo y promoción. Recuperado de http://www.sep.gob.mx/es/sep1/ cncm antecedentes\#.WCvb3aLhAfM

(2011). Plan de estudios 2011. Educación Básica. México: Autor. Recuperado de http://www.curriculobasica.sep.gob.mx/ images/PDF/planestudios11.pdf

SEP-SNTE (2011). Acuerdo para la Evaluación Universal de Docentes y Directivos en Servicio de Educación Básica. Recuperado de http://www.evaluacionuniversal.sep.gob.mx/ acuerdo.pdf 